\title{
La fragilidad de la democracia
}

\author{
Daniela Spenser
}

FRANCISCO ZAPATA (comp.), 2006

\section{Frágiles suturas. Chile a treinta años del gobierno de Salvador Allende}

El Colegio de México, México.

$\mathrm{P}$ or si hiciera falta decirlo, el mundo de hoy tiene severos problemas. Frágiles suturas es una elocuente contribución para explicarnos, a través del camino chileno hacia el socialismo, sus antecedentes, sus tribulaciones y su violación, cómo hemos llegado al punto de hoy. El trayecto fue minado y no todas las minas han sido desactivadas. El libro es también un intento por recoger las minas y desactivarlas por medio del análisis histórico, los testimonios y la memoria. No comparto la tesis de Isabel Turrent de que "el escenario internacional que enmarcó el experimento chileno desapareció con todos sus cimientos" (p. 59.) El pasado vive en el presente: la Rusia de los zares no desapareció con la creación de la Unión Soviética, así como ésta ha dejado profundas huellas en la Rusia de hoy. De la misma manera, los Estados Unidos de la época del presidente Monroe están transfigurados en los Estados Unidos que otro presidente, con una visión imperial, ha adaptado a nuevas fuentes de energía. Las continuidades históricas obli-

\section{Democracy's Frailty}

DANIELA SPENSER: Centro de Investigaciones y Estudios Superiores en Antropología SocialDistrito Federal, México. spenser@prodigy.net.mx

Desacatos, núm. 28, mayo-agosto 2008, pp. 207-210.

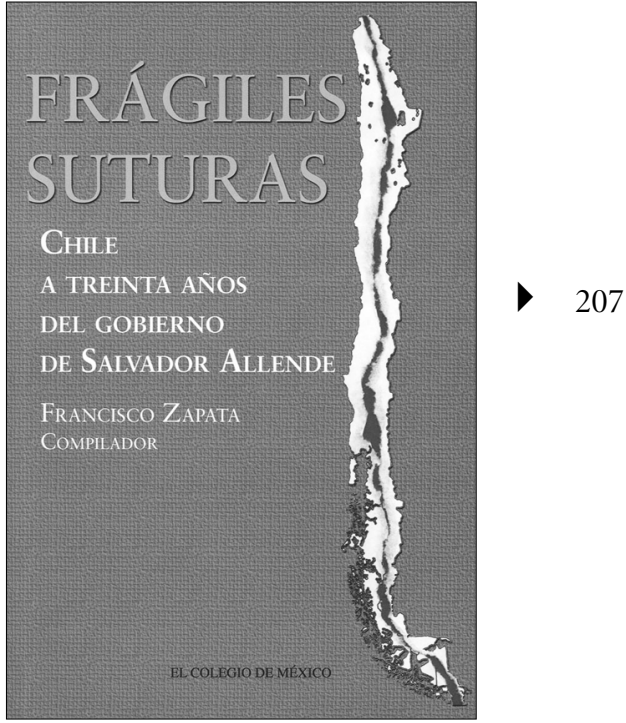

gan a una reevaluación constante del pasado y a que lo pongamos al día. Éste es uno de los objetivos logrado de Frágiles suturas.

El título del libro es afortunado y nos remite a la necesidad de una sociedad que quiere rehacer su vida en el presente y reconstruir la noción de su pasado después de una experiencia tan traumática como el golpe de Estado del 11 de septiembre de 1973. 
En el título del libro percibo un titubeo sobre si es posible suturar los lazos políticos y sociales en una sociedad que estaba acostumbrada a diferentes modales de convivencia, pero que fueron trastocados por la fuerza brutal que se instaló como otro modo de convivencia. Al recorrer la trayectoria histórica de Chile desde antes, durante y después del golpe, el libro nos permite avizorar la respuesta a la pregunta de qué tan frágiles son las suturas.

Después de hojear el libro decidí empezar a leerlo por el medio, dejando fluir las asociaciones que la lectura inspiraba. Actualmente es más fácil ver la inconmensurable responsabilidad de la CIA, de Henry Kissinger y de Richard Nixon en la caída del gobierno de Salvador Allende, por estar extensamente documentada en el capítulo de dios; pero es más difícil entender desde el interior de Chile las condiciones que hicieron posible el golpe. En el erudito, pero accesible, capítulo de José Valenzuela Feijóo sobre los aspectos económicos del gobierno de Allende, uno vuelve a enfrentar el dilema de la viabilidad de la vía pacífica al socialismo. ¿Fue Allende un Quijote que no entendió las relaciones capitalistas de producción, distribución y acumulación? Creo que lo primero que se desprende del análisis de Valenzuela es que, para Allende, la política y la ética eran inseparables. Cuando Allende llegó al poder en 1970 con 36\% de la anuencia de los electores, existían condiciones heredadas del pasado - el latifundio tradicional, la dominación del capital extranjero en el sector exportador $y$ un proceso de industriali-

zación trunca- que clamaban por un cambio estructural según los cánones de la más ortodoxa teoría de la modernización. Hasta los arquitectos de la Alianza para el Progreso - el instrumento estadounidense de la guerra fría para contrarrestar la influencia de la Revolución cubana- veían con buenos ojos la puesta en práctica de la reforma agraria. Esta vez, a diferencia de la administración de Eduardo Frei, el gobierno de Unidad Popular tenía la voluntad política, las riendas del poder de Estado y el apoyo de un amplio espectro de la población chilena para hacer los cambios necesarios con el objetivo de modernizar Chile.

¿Qué falló? Por un lado, la ingeniería de los instrumentos económicos no obedeció a la concepción que el gobierno tenía del proceso de cambio; por el otro, sobre el proceso en curso se montó la manipulación de los factores económicos por los adversarios del experimento chileno, de dentro y de fuera del país. Pero no sólo eso, los trabajadores de la industria ligera y de la extractiva abrazaron los postulados del socialismo y del poder popular que el compañero presidente representaba y quisieron hacerlos realidad sin mucho protocolo de por medio. Además del efecto económico en la baja de la producción y la productividad por la toma de las fábricas, sus consecuencias para los empresarios afectados fueron parte de los detonantes del ímpetu golpista.

Osvaldo Tello fue un dirigente en la mina de Chuquicamata que creía en la urgencia de la nacionalización del cobre. Al llegar Allende a la presidencia, Tello nos recuerda: "Nosotros sabíamos que habíamos logrado el gobierno, pero no el poder" (p. 275). Los obreros se organizaron para alcanzar la democracia sindical. No fue suficiente, pues su democracia no pudo contra los adversarios de la nacionalización y contra los golpistas que se propusieron sabotear la industria.

En el capítulo "Ser joven y no ser revolucionario. La juventud y el movimiento estudiantil durante la unidad popular" aparece fugazmente Elena, quien con la rabia a flor de piel se propuso dialogar con los militares para que desocuparan el recinto universitario, el lugar donde "se formaron los principales líderes políticos, gremiales y culturales del país, además de premios nacionales de literatura, historia, ciencias, teatro, música, un Premio Nobel de Literatura, un secretario general y un presidente de las Naciones Unidas", y contra el cual los golpistas se ensañaron con particular diligencia (p. 368). Cerca de cinco años antes, el 21 de agosto de 1968, los estudiantes checos salieron a las calles de la Praga de Franz Kafka, de José María Rilke, de Mozart, de Freud y del poeta Jan Neruda —de quien Pablo tomó su apellido - para dialogar con los imberbes soldados soviéticos y exhortar a los Koljas, a los Ivans, a los Sergueis, a que se regresaran a su tierra porque allí no encontrarían a una Natasha que los quisiera. Es por eso que los estudiantes que participaron en la Primavera de Praga se solidarizaron tan fácilmente con los chilenos. Para ellos, Allende se parecía a Dubcek, pues ambos creían que la verdad, su verdad, triunfaría.

Una de las preguntas que uno se 


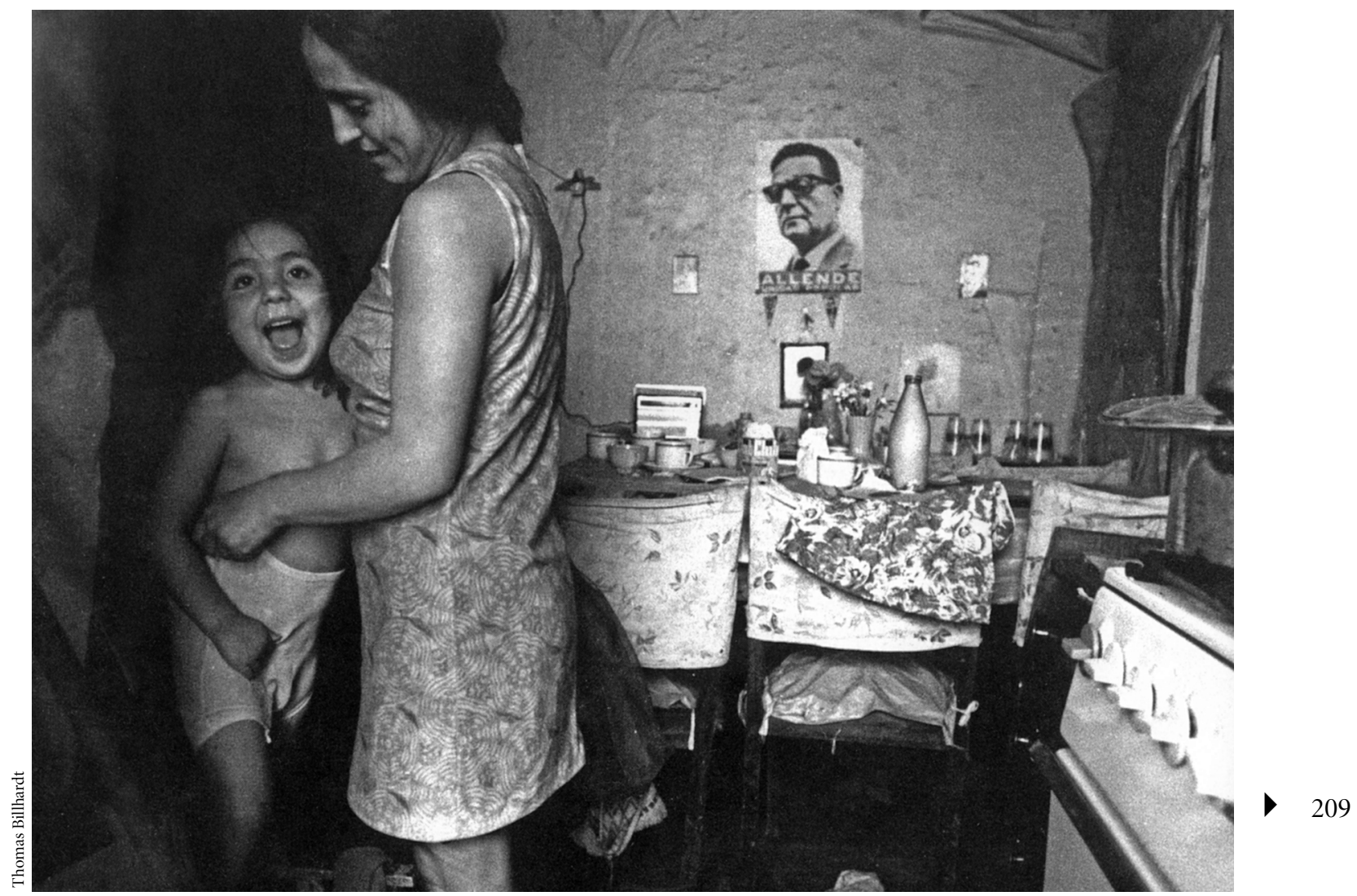

Imagen tomada del libro Salvador Allende. Una época en blanco y negro, El País, Aguilar, Buenos Aires, 1998.

hace hoy en día es si Allende fue tan ingenuo como para no sospechar de los intentos aviesos de los militares.

Fabio Moraga nos recuerda que en una visita a México llevada a cabo a finales de 1972, Allende habló de la historia de Chile: "[...] mi país, país democrático, con muy sólidas instituciones, país que tiene un Congreso en funciones hace 160 años, país en donde las Fuerzas Armadas [...] son Fuerzas Armadas profesionales, respetuosas de la ley y la voluntad popular" (p. 371). Allende, por supuesto, conocía los complots de una parte de los militares que tuvieron lugar en las décadas anteriores, analizados en el libro por Verónica Valdivia Ortiz, aunque "la mayoría de la oficialidad creía en el respeto a la Constitución" (p. 168). Allende tenía que saber que los militares eran anticomunistas y que su respeto a la Constitución —entendida como la defensa de la soberanía de la nación- no era necesariamente el respeto a la democracia. En realidad, la guerra fría condicionó el acatamiento a los preceptos de la democracia, cuya fragilidad se puso a prueba una y otra vez en Chile y en el resto de América Latina. Y las aliadas de la guerra fría eran las clases dominantes, cuyo poder económico se mermó en el Chile de la década de 1960 y que se derechizó en el proceso. Bajo el gobierno de Salvador Allende los militares querían y obtuvieron una mayor participación en la vida política de Chile, pero esta inclusión, parece, contribuyó a que los militares tomaran una postura a favor y en contra de la Unidad Popular desde dentro. Y desde ahí, junto con la derecha afectada por la vía chilena al socialismo, dieron el artero golpe de Estado.

El golpe institucionalizó la violencia - no cualquier violencia - y, a la sombra del terror, "el Estado fue apartado de sus funciones sociales y económi- 


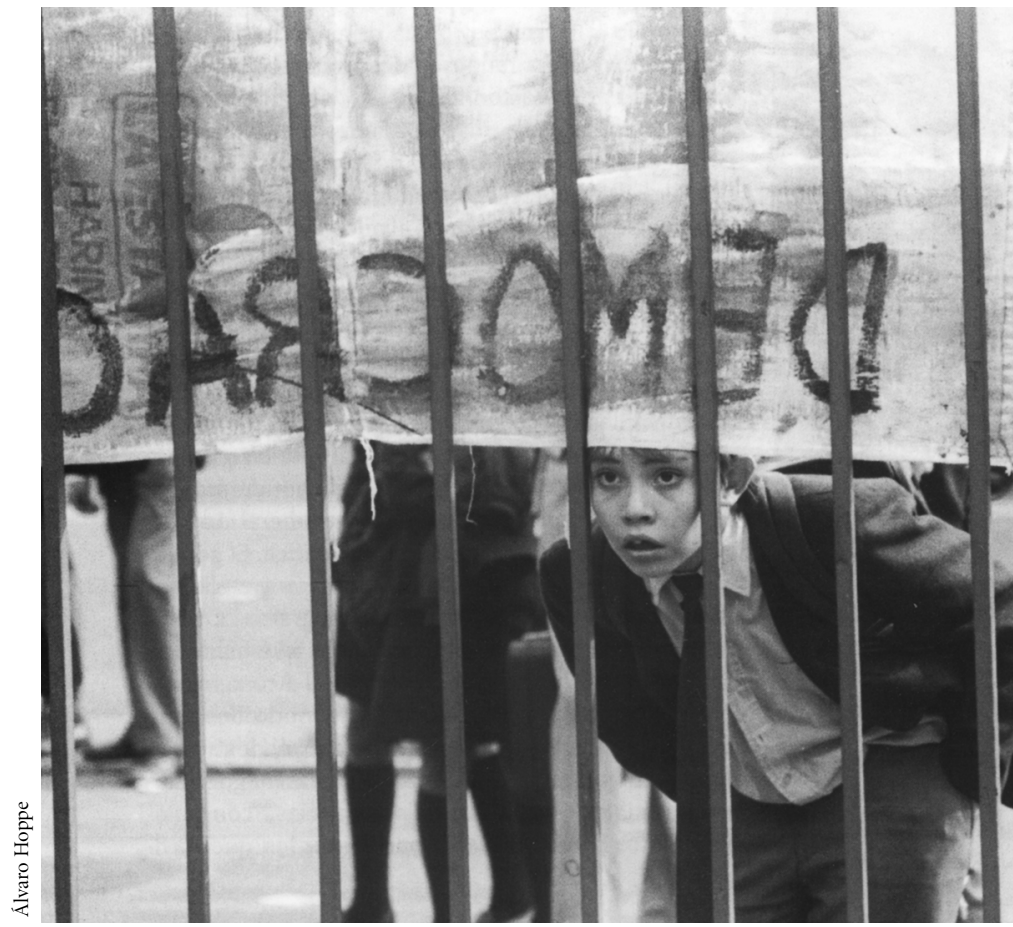

Imagen tomada del libro Salvador Allende. Una época en blanco y negro, El País, Aguilar, Buenos Aires, 1998.

cas para ser entregadas a los privados, primando una perspectiva individualista y atomizada de la sociedad" (p. 193). Frágiles suturas toca el tema de la violencia pinochetista solamente de paso, por pudor, por vergüenza, o por la razón que sea. Para reconciliar el sueño con la pesadilla que fue, el libro aborda ese pasado dramático y traumático por medio de metáforas y algunas reflexiones sobre su memoria. El incontable terror del Estado es tratado por Lessie Jo Frazier en su estudio de la transición del gobierno militar al gobierno civil, lo que nos permite vislumbrar una luz después de la oscuridad y que remite a la participación de la mujer, libre de ser vista — no en este libro— como una víctima sexualizada de la saña de los militares. Frazier la presenta más bien como una agente en la recuperación de la salud mental y de la ciudadanía. Sin embargo, también en el proceso de la recuperación de la normalidad la transición ha demostrado ser frágil, sobre todo por las dificultades de los regímenes civiles para enjuiciar a los asesinos.

La otra dificultad para que la transición sea verdaderamente liberadora del terrible pasado ha sido el intento de las administraciones posdictatoriales de alcanzar la reconciliación nacional por medio del olvido del terror y del recurso de la memoria como amnesia al presentar a los políticos torturados de entonces como enfermos mentales y pacientes de las instituciones de salud de ahora.

La batalla por la memoria incluye en Frágiles suturas un ejemplo de afanosa búsqueda del medio apto para dar cuenta de los acontecimientos extraordinarios en tiempos "de la lucha por la apropiación política de la reparación del dolor" y las luchas por la historia actual (p. 451). Angélica Illanes escogió imágenes y poesías para competir con otros medios de expresión más convencionales: "Es la obscena osadía de este año 3 , treinta veces 3 más 3 , adquiriendo el símbolo numérico toda la fuerza de su signo desplegada en la figura tridimensional de la memoria, quedando ésta envuelta en las turbulencias magnéticas de la temporalidad" (p. 450). El Chile de Allende, según esta autora, era "un cuaderno abierto para ser escrito por todos, colectivamente, en la medida en que fuésemos capaces de situarnos a la altura de aquellos que 'osaron repensar el mundo como un proyecto al servicio del hombre'” (p. 470).

Demasiados chilenos viven en el desencanto, recuerda Juan Pablo Cárdenas en su capítulo sobre el periodismo, silenciado por la dictadura y no del todo recuperado en la transición hacia la democracia. "Chile está enfermo de impunidad", concluye Pablo Yankelevich. Es por ello que Frágiles suturas es una alerta sobre la existencia de peligrosas minas que se quedaron en el camino y sobre la necesidad de recogerlas para que no nos estallen en la cara, como de hecho está sucediendo. 